\title{
DERECHO A LA IDENTIDAD PERSONAL, COMO RESULTADO DEL LIBRE DESARROLLO DE LA PERSONALIDAD
}

\section{Right to personal identity, as a result of the free development of the personality}

\author{
Marcela Leticia LÓPEZ SERNA ${ }^{1}$ \\ Julio César KALA ${ }^{2}$ \\ Sumario: \\ I. Introducción II. El derecho a la identidad III. El nombre IV. El libre desarrollo de la personalidad \\ como derecho humano V. La orientación sexual como elemento de ejercicio de la libertad personal VI. \\ Conclusiones VII. Mesografía
}

Resumen: La evolución de los derechos humanos ha permitido garantizar el goce de un ejercicio eficaz de cada vez mayor número de derechos, algunos de los cuales son derechos necesarios como medio operativo para el ejercicio de otros tantos derechos. El derecho a la identidad y al libre desarrollo de la personalidad es de estos derechos, sin los cuales sería imposible pensar en ejercer los derechos del orden civil, personal y familiar de los individuos. El desarrollo de estos derechos ha sido lento, pero consistente pues han engendrado un nuevo orden en las posibilidades de realización del proyecto de vida de las personas, solo estudiándolo en sus razones filosóficas más profundas, puede entenderse la defensa aguerrida que se hace de ellos.

Palabras clave: Posmodernidad, libre desarrollo de la personalidad, derechos humanos, nombre, identidad, género, sexo, matrimonio, sociedad.

Abstract: The evolution of the human rights has allow to guarantee the joy of an effective exercise of each time, bigger number of rights, some of which are necessary as operative media to exercise another rights. The right to identity and free development of personality are part of these rights, without them, it would be imposible to think about exercising the rights in the civil, personal a family order. The development of these rights has been slow, but consistent because it has engorged a new posibilities order for reaching the life Project of each one, just studying the deeper philosophical reasons, it can be understood the brave defending that come people make of it.

Key words: Posmodernity, right of free development of personality, human rights, name, identity, society, kind, sex, marriage.

\footnotetext{
${ }^{1}$ Lic. en derecho por la Universidad Autónoma de Aguascalientes, maestra en Derecho por la Universidad Nacional Autónoma de México, doctorante por la Universidad de Guanajuato en el Doctorado Interinstitucional de Derecho.

${ }^{2}$ Profesor de Departamento de Derecho, Universidad de Guanajuato.
} 


\section{Introducción}

Uno de los derechos humanos sobre los cuales actualmente se discute en gran número de foros es el denominado derecho al libre desarrollo de la personalidad, que según el máximo tribunal del país ha sido definido como la posibilidad de elegir de manera libre y autónoma el proyecto de vida que la persona desee realizar. Bajo esta perspectiva, se trata de una prerrogativa que en realidad es instrumental para la realización de muchos otros derechos, tales como la posibilidad de determinar su estado civil, la profesión, sus prácticas religiosas, su orientación sexual o simplemente las filias o fobias por las que desee decantarse.

En este sentido, las condiciones cotidianas que plantean la sociedad y el Estado, a través de su marco normativo y administrativo, deben ser las adecuadas para lograr eficazmente el goce inmediato de estas determinaciones personales sin necesidad de recurrir a medios jurisdiccionales para que ello ocurra, ya que esto deviene en una doble violación de los derechos humanos: la violación por sí misma y la discriminación que implica el tener que recurrir a instancias judiciales para lograr el respaldo de la autoridad para lograr el goce del derecho concreto, lo que no es necesario para todos los ciudadanos, y en ello radica esta idea de discriminación añadida.

Múltiples son los casos cotidianos en que se aprecia esta situación de vulneración de derechos humanos relacionados con el derecho al libre desarrollo de la personalidad. Por mencionar algunos, encontramos: el nombre, la imposibilidad de cambiarlo o elegirlo a libre voluntad, la determinación en documentos oficiales de la identidad respecto al género de la persona, cuando primigeniamente esto debería ser un asunto de elección personal, tanto su profesión, como la decisión de hacerlo público o no. Relacionado con esto, encontramos también el acceso al matrimonio, virtud a que muchas de las legislaciones del país siguen conteniendo dogmas al respecto de la necesidad de que esta institución ocurra, como requisito sine qua non, entre un hombre y una mujer.

Aunque grandes han sido los avances en materia de derechos humanos, particularmente en lo que respecta al derecho al libre desarrollo de la personalidad, seguimos adeudando leyes y procedimientos que sean acordes a las expectativas que de estos derechos se tienen: un disfrute inminente, justo en los mismos términos en que cualquier ciudadano puede acceder a ellos.

El cambio de paradigmas en materia de derechos humanos ha sido fuertemente impulsado por nuevas corrientes de pensamiento, orientadas en una visión posmoderna de la sociedad y su cultura, ya que han aportado argumentos ius filosóficos consistentes, determinantes para derribar grandes ataduras morales objetivadas a través de la legislación.

Una de las principales críticas que hace la posmodernidad a la modernidad es la historización que le es propia, por su creación de verdades hegemónicas en que se pretende sostener la existencia de una sola historia del hombre, una única línea del tiempo en la que se inscriben de manera homogénea para toda la humanidad las distintas fases tanto del pensamiento, del avance de la ciencia o bien, los hechos trascendentales, sin tomar en consideración la existencia de otras realidades.

Por su parte, en derecho nos hemos encargado de crear nuestra propia historia. Particularmente tratándose de derechos humanos, hay toda una narrativa de las fases por las que se supone que han pasado estas prerrogativas fundamentales. De esta suerte se ha creado la teoría 
de las generaciones de los derechos humanos, en que, de acuerdo a las ideologías políticas occidentales imperantes, se ha ido permitiendo de manera paulatina el goce de distintos derechos.

Aunque muchas son las críticas al respecto de la historización, rescatamos la señalada por David Sánchez, por considerar que las resume de manera breve:

la visión de los derechos humanos como derechos de primera, segunda y tercera generación sirve para reforzar un imaginario excesivamente eurocéntrico y lineal que, aunque posee sus virtualidades y elementos positivos, acaba por implantar una cultura anestesiada y circunscrita a una única forma hegemónica de ser humano, desarrollada por occidente en su trayectoria y versión de la modernidad burguesa y liberal ${ }^{3}$.

No obstante, esta línea del tiempo sirve para comprender la razón, virtud a la cual en nuestros días se discute el tema del libre desarrollo de la personalidad, un derecho en que no se había reparado abundantemente ya que las preocupaciones inmediatas de defensa se enfocaban en elementos más concretos, tales como el derecho a la vida, la propiedad o la libertad de movimiento.

Una vez que en determinadas sociedades se contó con el goce, relativamente generalizado, de estos primeros derechos garantizados en los textos legales, se estuvo en posibilidad de discutir otras así llamadas, todavía en algunas latitudes, garantías individuales. En ese sentido, procurando poner en el centro de la discusión a la persona, se fueron reconociendo distintas posibilidades de ejercicio, muchas de las cuales se circunscriben directamente al derecho civil en tanto al derecho de las personas.

El derecho del individuo de ser un individuo, con la capacidad de elegir por sí mismo qué derechos desea ejercitar y en qué términos hacerlo, se había dado por sobreentendido, en tanto se regulaban casuísticamente las posibilidades de determinación de su individualidad. Así tenemos que el derecho a contar con todos los atributos de la personalidad existe tanto en la doctrina jurídica como en la norma, desde los albores del derecho civil de nuestro país: el nombre, el domicilio, la nacionalidad, la capacidad, el patrimonio y el estado civil, son elementos a los que no sólo tiene posibilidad de acceder la persona en tanto ciudadano de nuestro país, sino incluso tiene derecho a ello y el sistema jurídico cuenta con elementos suficientes para poder garantizarlos.

No obstante, las posibilidades de ejercicio se han encontrado con limitaciones de carácter moral, con base en las cuales se sigue legislando aun contraviniendo principios básicos de los derechos humanos, tales como la universalidad y maximización de los mismos que, al menos en teoría, deberían verse coartados exclusivamente por la necesidad de no violentar los derechos de los terceros.

Dentro de las agendas legislativas de muchos congresos se discute la manera en que, en cumplimiento de las nuevas características constitucionales que deben poseer los derechos humanos, se pueda maximizar el goce de estas prerrogativas para los ciudadanos, respetando su libre albedrío en todo aquello que no trastoque cuestiones que por su carácter deban ser regidas estrictamente por el Estado, y en las que tampoco se veas afectados los derechos de los demás. De ahí que se haya acuñado un concepto tan amplio para incluir todos los derechos derivados de esta condición: el derecho al libre desarrollo de la personalidad.

\footnotetext{
3 SÁnchez Rubio, David (2011), "Sobre el concepto de historización, una crítica a la visión sobre las de- generaciones de derechos humanos”, Praxis, Colombia, 67, julio - diciembre, pp. 9-22.
} 


\section{El derecho a la identidad}

El derecho al libre desarrollo de la personalidad no puede desvincularse del derecho a la identidad, pues es imposible imaginar el ejercicio del primero sin contar con el segundo y viceversa. Es decir, es como lo ha dicho la Suprema Corte de Justicia de la Nación respecto del derecho a la información: se distingue de otros derechos intangibles por su doble carácter: como un derecho en sí mismo y como un medio o instrumento para el ejercicio de otros derechos ${ }^{4}$. Asimismo, se ha pronunciado sobre el derecho a la identidad precisando que se configura no solo por el reconocimiento de su origen biológico sino por su realidad social [...] la identidad no se agota en lo biológico. La formación de la identidad se construye a través de múltiples factores psicológicos y sociales de la manera en la que el individuo se concibe ${ }^{5}$.

Así, dependiendo de la visión que el individuo tenga de sí mismo, se determinarán aquellas cuestiones con las que se identifica para el resto de las áreas de su vida íntima, privada, familiar, profesional, política, social y en general para todas aquellas en las que, como persona tenga injerencia.

El tema de la identidad ha sido tradicionalmente interpretado como un derecho de la personalidad que se vincula con otros derechos derivados de la filiación, tales como el derecho a tener una nacionalidad, los derechos alimentarios, el derecho a mantener un vínculo con los padres ${ }^{6}$, llegando a considerarse como violencia la omisión de registrar civilmente a los menores a una edad temprana, pues este acto implica el reconocimiento del estado, de la existencia del individuo en primera instancia, de un vínculo formal entre la entelequia estatal y el individuo que deviene en una serie de prerrogativas derivadas de la calidad de ciudadano mexicano.

El derecho a la identidad ha sido adscrito dogmática y jurídicamente, primigeniamente al derecho civil, como un elemento esencial del derecho de las personas, para ser únicas en su especie, para poder diferenciarlas del resto de los componentes de la sociedad, haciéndolos objeto de derechos y obligaciones concretas en tanto a su identificación individual, a las relaciones jurídicas de las que sea parte o en las que como tercero, sea afectado. Esta visión pragmática de la identidad sirve al derecho como medio de determinación de aquellos que son sujetos tanto de derechos, como de obligaciones. De tal suerte que en materia procesal devienen en requisito sine qua non para su participación en cualquier clase de controversia judicial, llevándose a cabo siempre un concienzudo examen de la personalidad de las partes.

La identidad como derecho implica las características y rasgos que le son propios al individuo y que además sirven de elementos para diferenciarlo del resto, ya sea del orden físico, biológico, social o jurídico. Respecto a este último, primordialmente a través del nombre se le suele relacionar a un entorno familiar con las consecuencias jurídicas que esto conlleva: el parentesco, la filiación, la maternidad, la paternidad o los alimentos.

Pero este derecho va más allá de la posibilidad de poseer estas características en el sentido que la sociedad o el Estado desee otorgárselos o imponérselos al individuo. Al ser un derecho, la persona debe poder tener la potestad suficiente para elegir por sí mismo

\footnotetext{
4 Tesis P./J. 54/2008 (9a), Semanario Judicial de la Federación y su Gaceta, Novena Época, t. XXVII, abril de 20o8, p. 1563.

5 Tesis $1^{\mathrm{a}} \mathrm{L}$ XXIII./2017 ( $10^{\mathrm{a}}$ ), Semanario Judicial de la Federación y su Gaceta, Décima Época, t. I, junio de 2017, p. 580 .

6 González Contró, Mónica (2011), "Reflexiones sobre el derecho a la identidad en niños, niñas y adolescentes en México, Boletín mexicano de derecho comparado, México, núm. 130, enero-abril 2011, http://www.scielo.org. $\mathrm{mx} /$ scielo.php?pid=So041-86332011000100004\&script=sci_arttext
} 
todas aquellas características que le afecten exclusivamente de manera personal y en las que de ninguna forma se vean comprometidas las prerrogativas de un tercero, lo que a final de cuentas es característica de un estado moderno liberal.

Es en esta medida que la discusión sobre este derecho, se centra, más allá de la necesidad que se tiene de que cada cual posea unas características que ayuden al resto, incluido el Estado, a identificarlos, en el hecho de que esas características, en tanto que sean propias del individuo, puedan ser determinadas por el individuo, por sí mismo, garantizándose los medios administrativos y jurisdiccionales, por los cuales sea posible el ejercicio del derecho a la identidad en estos términos, favoreciendo el derecho al libre desarrollo de la personalidad.

\section{El nombre}

Este medio de identificación forma parte de los atributos de la persona, tanto física como moral y ha sido definido por Henri Leon Mazeaud como la palabra o vocativo que designa a una persona $a^{7}$. Sin embargo, esa designación hace parte tan profunda de la relación de la persona con su entorno que ha sido indispensable incluirlo en la discusión sobre el libre desarrollo de la personalidad, para permitir debatir el que sea el propio usuario del nombre quien pueda determinar con cuál de ellos debe ser nombrado y definido.

La historia de esta lucha ha transitado por diversas fases, desde el tema de la configuración del nombre en sus elementos constitutivos. Actualmente en nuestro país, el nombre debe estar conformado por un nombre propio y dos apellidos, garantizando que independientemente de la condición familiar o de reconocimiento de la paternidad o maternidad de los progenitores, los menores y en general cualquier persona pueda acceder a un nombre con las mismas características de composición que el resto de la comunidad, evitándose las suposiciones o críticas sobre el origen de la persona, rompiendo de manera contundente con el test de legitimidad a que se hacían acreedores quienes, por cualquier razón, no contaban con ambos apellidos.

Sobre esto se ha ido más allá. Las sociedades patriarcales como la mexicana han determinado históricamente la jerarquía de los apellidos paternos por sobre los maternos, quedando relegado este último al segundo lugar en la lista de aparición en el nombre, lo que invariablemente deviene en la pérdida del apellido materno en una segunda generación, ocurriendo simplemente por una determinación arbitraria que obedece a esa prevalencia de la figura paterna que se arrastra en nuestra cultura occidental desde la figura del pater familiae romano. Como consecuencia, la discusión ha estado presente tratando de rescatar la igualdad de ambos progenitores en la posibilidad de legar su apellido, desvirtuando la existencia de razones objetivas en que pudiera estar fundada esta tradición.

Consecuentemente, las diversas legislaciones civiles han comenzado a incluir en sus textos enunciados normativos que permitan, de manera libre a los padres, determinar el orden que tendrán los apellidos de sus hijos, instaurándose como condicionante que ese acuerdo perdure para todos los descendientes que en común procree. Así se observa en el segundo párrafo del artículo 53 de Código Civil de Aguascalientes:

El nombre del registrado estará constituido por nombre propio así como por el primer apellido del padre y el primer apellido de la madre, en el orden que de común acuerdo determinen los padres; el orden de los apellidos del primogénito deberá aplicarse para los hijos nacidos poste-

\footnotetext{
7 Mazeaud, Henri, Leon y Jean (1959), Leçons de Droit Civil, séptima edición, Paris, ediciones Montchrestien, $12^{\circ}$ volumen, tomo I, p. 73.
} 
riormente con el mismo vínculo y en caso de que no exista acuerdo entre los padres, el Oficial del Registro Civil determinará el orden de los apellidos mediante sorteo. ${ }^{8}$

Difícil es lograr una medida que revierta toda una historia social de prevalencia de los patronímicos; ni siquiera para esta reforma que pretende restituir los derechos de las mujeres al contar con la posibilidad de heredar su apellido lo ha logrado a cabalidad. La crítica es certera, en todo caso siempre deberá incluirse el apellido paterno de la madre, quedando relegado de nueva cuenta el apellido de las mujeres, en este caso el de las ascendientes en segundo y ulteriores grados, al ostracismo de la normatividad civil.

Las limitantes en las que se justifica que la reforma no haya ido más allá, cubriendo también las críticas antes expuestas, radican en cuestiones pragmáticas del orden administrativo de identificación de la persona, que bien podrían ser salvadas a través de medios electrónicos diversos o contenedores de bases de datos amplias en que de una u otra forma se logre determinar a la persona en sus relaciones civiles, de parentesco y hacia el Estado.

Otros problemas que se han tenido que abordar, al respecto del nombre, se han hecho especialmente visibles luego de la nueva visión de los derechos humanos, impulsada por la reforma en materia constitucional de 2011, a través de la cual se pretende que estas prerrogativas puedan ser usadas en su máximo esplendor por sus acreedores. Así pues, el nombre, en su función de identificación de la persona en sus distintas facetas, no debe ser cargado como una lapa que atraiga la denostación o discriminación para la persona sino, más bien, como un medio a través del cual la persona se sienta plenamente identificada con lo que de acuerdo a su propia perspectiva define su esencia.

En este sentido, las condiciones actuales plantean nuevos retos que requieren soluciones inmediatas, acordes al respeto que se debe a la dignidad personal. Una de estas condicionantes son los cada vez más frecuentes casos de cambio de género, entendido en el sentido que le dota Marta Lamas: En castellano género es un concepto taxonómico útil para clasificar a qué especie, tipo o clase pertenece alguien o algo; como conjunto de personas con un sexo común se habla de las mujeres y los hombres como género femenino y género masculino?.

Partiendo de los principios generales del derecho de que lo accesorio sigue la suerte de lo principal y que el que puede lo más, puede lo menos, resulta evidente que si una persona decide realizarse una cirugía de reasignación sexual, o simplemente, si determina que es su deseo, aun sin este procedimiento quirúrgico, el ser reconocido socialmente como alguien con un género distinto a aquél con el que se le conoció en el momento de su nacimiento, sería contradictorio que deba, por mandato jurídico, conservar el uso de su nombre primigenio aun y cuando éste no sea acorde al nuevo sexo asignado, lo que provocaría de nueva cuenta el riesgo de discriminaciones para la persona.

De acuerdo a la radiografía que hace Octavio Paz, de la mexicanidad en su Laberinto de la Soledad ${ }^{10}$, los mexicanos somos sarcásticos, nuestro humor es cuando menos mordaz, por lo que de manera reiterada hacemos de cuestiones simples, como el nombre de las personas, un

8 Código Civil de Aguascalientes, [en línea] disponible en: http://www.poderjudicialags.gob.mx/images/Archivos/PDF/Estatales/Codigos/Cod\%2oCivil\%202.pdf.

9 Lamas, Marta (2000), "Diferencia de sexo, género y diferencia sexual", Cuicuilco Revista de Ciencias Antropológicas, Ciudad de México, 200o, vol. 7, núm. 18, enero-abril, p. 2, [en línea] disponible en: http://www.redalyc.org/ articulo.oa?id $=35101807$

${ }^{10}$ PAz, Octavio (2004), El laberinto de la soledad, Posdata, Vuelta a "El laberinto de la soledad, 4 a ed., México, Fondo de Cultura Económica, p. 26. 
motivo suficiente para generar la sorna y el escarnio de la comunidad, provocando la degradación de la persona.

Ésta y muchas situaciones análogas se viven diariamente por la simple limitación a la persona de decidir la manera en que quiere ser conocido, cuando, visto desde la distancia, se aprecia que la prohibición no estriba en que su permisión pudiera conllevar el detrimento de algún derecho de terceros, sino exclusivamente en cuestiones operativas de la administración pública que pondera como superior la facilidad de identificación de sus ciudadanos según el registro original que de ellos se hizo, por sobre la maximización de los derechos, lo que además tampoco implicaría necesariamente descontrol en la identificación de las personas, sino simplemente la necesidad de encontrar nuevas formas de organización que, ante todo, favorezcan el respeto de los derechos de los individuos.

Aunque la mejor solución para erradicar este tipo de violaciones radica, como siempre, en la educación de la sociedad, el derecho debe aportar soluciones que de manera inmediata resuelvan los conflictos desarrollados en el seno del pueblo al que regula, favoreciendo la convivencia pacífica y el respeto y tolerancia de los derechos humanos.

\section{El libre desarrollo de la personalidad como derecho humano}

Contar con los medios adecuados para la consecución de determinados fines suele ser tan importante como el fin en sí mismo. La posibilidad de desarrollar de manera libre la personalidad es el medio a través del cual se puede conseguir el ejercicio pleno del resto de los derechos que atañen a la persona en su fuero interno y en su interacción con la sociedad.

La libertad a la que se refiere el concepto de este nuevo derecho al libre desarrollo de la personalidad reside en una concepción del ejercicio de los derechos, que va más allá de la idea de universalidad que les es propio, ya que implica la acepción desarrollada por Lucy Taylor de la diversalidad ${ }^{11}$ en el sentido de que los derechos deben ser factibles en la realidad del día a día de todos los ciudadanos; pero para que esto ocurra se debe ampliar la posibilidad de su ejercicio a las necesidades diversas que requiera cada cual en su otredad.

Parece ser que el medio más simple es cumplir con los requisitos básicos que exige la creación de una norma cuyos sus enunciados normativos sean generales, abstractos e impersonales, en el sentido de que la norma sea tan amplia que en un mismo supuesto quepan situaciones personales diversas, otorgando su goce a personas que son distintas y cuya cosmovisión también lo es.

El máximo tribunal del país ha definido la manera en que debe ser entendido este derecho, así como los elementos que incluye:

De la dignidad humana, como derecho fundamental superior reconocido por el orden jurídico mexicano, deriva, entre otros derechos personalísimos, el de todo individuo a elegir en forma libre y autónoma su proyecto de vida. Así, acorde a la doctrina y jurisprudencia comparadas, tal derecho es el reconocimiento del Estado sobre la facultad natural de toda persona a ser individualmente como quiere ser, sin coacción ni controles injustificados, con el fin de cumplir las metas u objetivos que se ha fijado, de acuerdo con sus valores, ideas, expectativas, gustos, etcétera. Por tanto, el libre desarrollo de la personalidad comprende, entre otras expresiones, la libertad de contraer matrimonio o no hacerlo; de procrear hijos y cuántos, o bien, decidir no tenerlos; de escoger su apariencia personal; su profesión o actividad laboral, así como la libre opción sexual, en tanto que todos estos aspectos son parte de la forma en que

\footnotetext{
${ }^{11}$ TAYLOR, Lucy (2013), "Decolonizing citinzenship: reflections on the coloniality of power in Argentina”, Conferencia dictada en Universidad de Guanajuato, trad. Lucy Taylor.
} 
una persona desea proyectarse y vivir su vida y que, por tanto, sólo a ella corresponde decidir autónomamente ${ }^{12}$.

Una de las controversias que más acaloradamente se siguen planteando sobre este derecho es la correspondiente a los controles que debe tener. Debido a que la Corte ha establecido que dichos límites no deben ser injustificados, las facciones más conservadoras se empeñan en buscar razones que, aun cuando perturben el libre ejercicio del desarrollo de la personalidad, logren garantizar el status quo en términos de la moral de esos grupos, cimentando en las aplastantes mayorías lo que no se puede defender en términos constitucionales.

Un vértice logró escapar a esta manera de legislar: el divorcio incausado es una realidad en muchas de las legislaciones del país; precisamente anteponiendo el derecho al libre desarrollo de la personalidad como base para su inmediata procedencia. Esto es así ya que, de acuerdo a múltiples teorías del matrimonio, esta institución se constituye a través de un acto contractual que, siguiendo las reglas del derecho civil, tendría que contar decididamente con el principio de autonomía de la voluntad para poder darle término en el momento en que cualquiera de las partes así lo determinara.

Hay que recordar que a través de la teoría de las obligaciones, son elementos esenciales de los contratos los sujetos, el objeto lícito y posible, las solemnidades y el consentimiento13, por lo que si en determinado momento dejara de existir la voluntad de continuar dentro del matrimonio, la ley debe contemplar salidas para finiquitar el instrumento jurídico contractual de manera inmediata; evidentemente dejando a salvo los derechos que pudieran controvertirse, pero respetando ante todo la libre voluntad de los sujetos.

Y es que las relaciones de pareja han cambiado tangencialmente de cómo las concebían nuestros antepasados; estas también evolucionan, se abren y cierran diversos ciclos amorosos. Cada vez más a menudo ha ocurrido una simplificación de las pruebas que esa experiencia debe superar para ser considerada como amor. No es que más gente esté a la altura de los estándares del amor en más ocasiones, sino que esos estándares son ahora más bajos: como consecuencia, el conjunto de experiencias definidas con el término amor se ha ampliado enormemente ${ }^{14}$.

Esa liquidez que se le ha dado hoy a la figura del amor deviene en la necesidad de facilitar también los procedimientos jurisdiccionales y administrativos para que la voluntad y su ausencia puedan ser materializadas en instituciones como el matrimonio y la respectiva disolución de este vínculo, pero también con el aumento de consecuencias de derecho para las figuras de facto que cada vez suelen ser más frecuentes en el modus vivendi de las familias actuales. Es en esa medida que el concubinato ha ganado parcelas importantes en materia de alimentos y derechos sucesorios.

La evolución del derecho nos ha llevado por sendas previamente exploradas por sociólogos y filósofos que han ayudado a desentrañar la esencia de la persona, para de esta forma, poder establecer quiénes son aquellos destinatarios de los derechos humanos y, en su caso, cuál es ese universo hasta el cual alcanzan a materializarse. La pregunta surge de las situaciones fácticas que son visibles cada vez más con la amplia cobertura de los medios de comunicación y las redes sociales, en donde se pueden apreciar crímenes y violaciones de derechos humanos en

\footnotetext{
${ }^{12}$ Tesis LXVI/2009, Semanario Judicial de la Federación y su Gaceta, Novena Época, t. XXX, diciembre de 2009, p. 7

13 Bejarano Sánchez, Manuel (2015), Obligaciones civiles, 6a ed., México, Oxford, p. 46

14 Bauman, Zygmunt (2015), Amor líquido, trad. de Mirta Rosenberg y Jaime Arrambide, Fondo de Cultura Económica, p. 19.
} 
cualquier lugar y hora y con receptores diversos, pero en los que se cuenta con una variable común: el hecho de que el emisor de estas vejaciones se considera diferente a su víctima, tan distinto que no considera que esté perpetrando actos que vulneran la condición humana de un semejante, sino, en todo caso, de algo que ni siquiera alcanza a tener el calificativo de persona.

Esta visión tiene sus orígenes en la modernidad, en la idea de la existencia de verdades hegemónicas de las que nació el egocentrismo del yo que concibe como exclusiva su propia verdad y que, por tanto, conceptúa a la persona desde su particular visión, excluyendo de esta categoría a quienes difieran sustancialmente de lo que ese yo, occidentalizado, es. Charles Taylor repara en este hecho ${ }^{15}$ encontrándolo como causa fundamental de gran parte de los crímenes que de manera reiterativa lastiman a nuestras sociedades. Falta que el individuo vea al otro como alguien de su misma condición. En esa medida podrá entender que, precisamente por ser también una persona, tiene filias y fobias que le son exclusivas y ello no lo hace menos merecedor de la protección de sus derechos, ni debería necesitar la aprobación de los otros para poder ejercitarlos con libertad.

Las sociedades evolucionan vertiginosamente, lo que nos enfrenta al desafío de adaptar a ese mismo paso la legislación vigente, para que pueda ceñir adecuadamente a la población a que se debe un núcleo social heterogéneo en que las condiciones individuales de cada cual son diversas, pero no por ello deberá atenderse exclusivamente los intereses de unos dejando de lado los de los otros.

\section{La orientación sexual como elemento de ejercicio de la libertad personal}

Por antonomasia, el derecho regula la conducta externa del hombre en sociedad, quedando al libre albedrío del individuo las parcelas más internas, las que atañen exclusivamente al individuo. El ejercicio de la sexualidad por sí mismo es algo que debe escapar de la regulación legal, salvo cuando ese ejercicio implica la correlación con otro individuo. Entonces, sí deberá revisarse, en primera instancia, la existencia de consenso y que no exista daño en la esfera jurídica de ese otro ente, en cuyo caso, evidentemente deberá intervenir la juridicidad en la restitución del afectado en su esfera de derechos, o al menos en compensar en la medida de lo posible el daño sufrido.

En esta medida, el reclamo del libre ejercicio de la sexualidad, como una arista del derecho al libre desarrollo de la personalidad y por tanto una manera de ejercer la identidad personal, es una de las encomiendas pendientes de reconocerse de manera precisa en la mayor parte de las legislaciones civiles de nuestro país.

La discusión engendra principalmente dos vertientes: la referente al ejercicio de la sexualidad personal como elemento de identificación de género; de si se es mujer u hombre, y la tendente a definir las relaciones de pareja que el individuo entabla. Es importante esta dicotomía pues pone de relevancia algunas circunstancias que, vistas a la luz del derecho, no hacen más que reafirmar el compromiso que el derecho debe asumir con la maximización de los derechos de las personas:

1. Si el ejercicio de la sexualidad en lo individual, se plantea como un simple criterio de identificación de las personas, no parece resultar, per se, una razón suficiente como para limitar la libertad en su determinación por parte del propio individuo.

\footnotetext{
${ }_{15}$ TAYlor, Charles (2006), Fuentes del yo, la construcción de la identidad moderna, Barcelona, Paidos, p. 45.
} 
2. Si la determinación del género al que se quiere adscribir la persona, es algo que exclusivamente trae consecuencias en su esfera personal, no se observan elementos de conducta externa en los que tenga que tener injerencia el derecho, por lo que debería ser una de esas regiones en las que solo la conciencia de la persona pueda ejercer mandato.

3. Si la conciencia del individuo no encuentra referente con ningunos de los dos géneros consuetudinariamente utilizados, resultan insuficientes las razones de tradición o cultura para necesariamente suscribirlo en uno de ellos, o para prohibirle que se auto conciba en una categoría alterna, pues, en todo caso no repara perjuicio en tercera persona con esa decisión.

4. Si la voluntad de las partes es el principio por excelencia en las relaciones civiles, no existiendo entre estas, discordancia, resulta innecesaria la prohibición del derecho en relaciones jurídicas consensuales, sin importar si estas relaciones ocurren en términos distintos a las conductas tradicionalmente observadas en la sociedad.

5. Bajo esta tesitura, un estado liberal debe mantener un límite claro de las áreas de ejercicio de la vida privada de las personas en las que puede incursionar y cuáles son determinación exclusiva del individuo, so pena de convertirse en un estado de moral y no de derecho.

La posmodernidad es definida como la etapa de la humanidad en la que es posible encontrar diversidad en todas partes. Palpar la diferencia en todos los ámbitos se ha convertido en lo más cotidiano, la sexualidad es quizá el más representativo de todos esos ámbitos.

Dentro de esta vorágine de divergencias existen quienes, como señala Richard Rorty, afirman que ser mujer no cuenta como una de las maneras de ser humano. El no ser varón es el tercer modo de no ser humano ${ }^{16}$ y esta discriminación aplica por supuesto también para quienes no se definen como varón, aun cuando biológicamente hayan nacido con esta determinación genética y, evidentemente, cuando el individuo no encuadra en ninguna de las dos categorías socialmente reconocidas.

Aún y cuando cada día se implementan medidas de reconocimiento y respeto de la identidad sexual y el ejercicio de la misma, los cuestionamientos tratan de abordar la raíz de fondo de este dilema, que pareciera ser la innecesaria intromisión del estado en la determinación del género y el ejercicio de la sexualidad de las personas. Y es que basta observar el funcionamiento del estado para darse cuenta de que todo está diseñado de manera dicotómica, o se es hombre o mujer; no existen más posibilidades ni en los atestados del registro civil, ni en el diseño de los textos normativos, vaya, ni siquiera en la construcción de los servicios sanitarios de los edificios públicos.

De ahí que ya se estén desarrollando en otras latitudes teorías que pretenden resolver la controversia, aportando razonamientos para demostrar la vacuidad de esta determinación genérica dual, pero más aún, para denunciar los efectos de vulneración de la libertad en el desarrollo de la personalidad y el derecho de la identidad de las personas que las mismas traen aparejadas.

El sexo neutro aparece como ese concepto que puede englobar todas las posibilidades porque no encasilla a ninguna de ellas, incluso, como su nombre lo dice, no se atreve a juzgar la posibilidad de que la cuestión sexual sea algo que pueda (y mucho menos, deba) ser encasillado

\footnotetext{
${ }^{16}$ RoRTy, Richard (1993), "Derechos humanos, racionalidad y sentimentalismo", The Yale Review, E.U.A. vol. 81, núm. 4, octubre, p. 3 .
} 
en un número concreto de posibilidades, porque es algo tan diverso como el número mismo de individuos, pues cada cual debe poder contar con la posibilidad de autodefinirse de manera independiente a las opciones que el estado o la sociedad decida ofrecerle.

Como consecuencia, el estado debería redefinir esa red relacional que en torno al género de las personas ha construido, evidentemente eliminar de los actos administrativos la determinación del género de las personas pues, en términos de la teoría de la protección de los datos personales, este tendría que ser un dato sensible que le ocupe solamente a su poseedor. Por tanto, la identidad sexual de las personas deberá dejar de ser un obstáculo para el ejercicio del resto de los derechos de la persona, y tendrá que ser un derecho en sí mismo, a través del cual se pueda acercar más al individuo a alcanzar la concreción de su proyecto de vida.

\section{Conclusiones}

Las paradojas de la era que vivimos nos obligan a examinar la verdadera ratio legis de la norma que nos rige, revisar la legitimidad de esos postulados en el sentido de que efectivamente la norma sea acorde con las necesidades de las personas que habitan la comunidad en el momento concreto.

Ese test indiscutiblemente debe ocurrir desde la mirada de la tolerancia, entendiendo, hoy más que nunca, que las diferencias no deben alejarnos de los otros sino, más bien, ser motivo de cohesión, de interés por la alteridad, comprendiendo que si uno solo de los derechos, aún y cuando sean los de alguien más, son vulnerados, el daño lo sufre todo el sistema normativo. Es indispensable buscar prevalecer en todo momento el derecho del otro, marcando como exclusivo límite el comienzo de la esfera jurídica de otro individuo.

Las violaciones a los derechos humanos suelen ser más frecuentes cuando se les normaliza, cuando no se reconoce en ellas la existencia del daño perpetrado. Los obstáculos al ejercicio del derecho al libre desarrollo de la personalidad a través de la libre determinación de la propia identidad y el ejercicio y elección de la sexualidad son de este tipo. Las cometemos cotidianamente sin reparar en lo que estamos haciendo porque la costumbre llega a ser más fuerte que el principio de respeto al prójimo. Esto se ve favorecido considerablemente por la institucionalización de eso que causa molestia, es decir, si es el propio estado, actuando con su posición de imperio quien dispone que las cosas deban ser llamadas de tal o cual forma, si la propia norma dispone que las posibilidades de ser son limitadas a las que ella misma ofrece y lo dice en su condición de entelequia omnipresente y todo poderosa, que cuenta con la posibilidad de la coacción, entonces no existe nada por discutir. Esos enunciados son verdad legal y deben ser obedecidos no sólo de manera ciega, sino incluso considerárseles razonables y sustentados en el tamizaje de la lógica.

El verdadero problema viene cuando, como hoy, nos encontramos con severas inconsistencias que producen verdaderas antinomias en las leyes reglamentarias respecto a principios constitucionales como el de igualdad, la que vemos que les es vedada a quienes deciden disidir de lo que se considera normal. Es entonces cuando el perímetro de la libertad de ejercicio de los derechos se hace presente y limita ostensiblemente las personalidades de aquellos que son los otros. De tal suerte, el derecho debe auto examinarse constantemente para revisar aquellas categorías a las que hoy se les conoce como sospechosas y en término de las cuales pueda estarse constituyendo una violación de los derechos humanos. 


\section{Mesografía}

Bauman, Z. (2006). Ética posmoderna. México: Siglo XXI editores.

(2015), Amor líquido, trad. de Mirta Rosenberg y Jaime Arrambide, Fondo de Cultura Económica, p. 19.

Bejarano Sánchez, Manuel (2015), Obligaciones civiles, 6ª ed. México, Oxford, p. 534.

Mazeaud, Henri, Leon y Jean (1959), Leçons de Droit Civil, séptima edición, Paris, ediciones Montchrestien, $12^{\circ}$ volumen, tomo I, p. 238.

Paz, Octavio (2004), El laberinto de la soledad, Posdata, Vuelta a "El laberinto de la soledad",

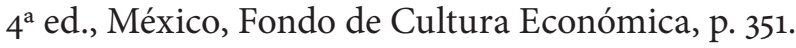

TAYlor, Charles (2006), Fuentes del yo, la construcción de la identidad moderna, Barcelona, Paidos, p. 797

\section{Hemerografía}

SÁnChez Rubio, David (2011), “Sobre el concepto de historización, una crítica a la visión sobre las de- generaciones de derechos humanos", Praxis, Colombia, 2011, 67, julio - diciembre, p. 9- 22.

Lamas, Marta (200o), "Diferencia de sexo, género y diferencia sexual”, Cuicuilco Revista de Ciencias Antropológicas, Ciudad de México, 200o, vol. 7, núm. 18, enero - abril, p. 1-22.

RoRTY, Richard (1993), "Derechos humanos, racionalidad y sentimentalismo", The Yale Review, E.U.A., 1993, vol. 81, núm. 4, octubre, p. 1-20

\section{Conferencias}

TAYLOR, Lucy (2013), "Decolonizing citinzenship: reflections on the coloniality of power in Argentina”, Conferencia dictada en la Universidad de Guanajuato, trad. Lucy Taylor. 